\title{
Variations in Soil Carbon Stocks with Texture and Previous Landuse in North-western NSW, Australia
}

\author{
Peter Heywood $^{1} \&$ Simon Turpin ${ }^{2}$ \\ ${ }^{1}$ Research Associate, Crawford School of Economics and Government, Australian National University, Australia \\ ${ }^{2}$ Catchment Officer, Namoi Catchment Management Authority, Gunnedah, NSW, Australia \\ Correspondence: Peter Heywood, Research Associate, Crawford School of Economics and Government, \\ Australian National University, Australia. E-mail: pfheywood@gmail.com
}

Received: December 5, 2012 Accepted: February 4, 2013 Online Published: February 17, 2013

doi:10.5539/sar.v2n2p124

URL: http://dx.doi.org/10.5539/sar.v2n2p124

\begin{abstract}
Australia's land managers will need specific information about the best locations at which to sequester carbon if they are to take advantage of the recent Carbon Farming Initiative of the Australian Government under which carbon offsets can be created through sequestration of carbon in soil and trees. The literature indicates that soil texture and previous landuse are important determinants of soil carbon content. This paper describes the results of work to assess the current levels of soil carbon and the extent to which they vary with previous landuse and soil texture in the Namoi Catchment Management Authority in North West NSW, Australia. Soil samples were taken at 74 sites for determination of soil carbon concentration and stocks as well as soil texture and landuse in the last 10 years. There was wide variation between sites in soil carbon concentration and stocks which were greatest in those soils which had not been disturbed by cultivation and in soils with higher clay content. Thus, the greatest potential for carbon sequestration is in soils with the lowest carbon concentration, those which have been previously disturbed, and with higher clay content. Maintaining any increased carbon concentration will depend on minimizing disturbance, increased carbon input and minimizing loss of carbon through soil erosion. As these factors all vary significantly on a regional and landscape basis it will be important for land managers to have access to information which allows them to choose the sites at which potential for sequestration of soil carbon is greatest.
\end{abstract}

Keywords: soil carbon, texture, landuse, Australia

\section{Introduction}

Although Australia has set a target for reduction of greenhouse gas (GHG) emissions, the most recent data indicate that this will be difficult to meet with current mitigation practices (DCCEE, 2012). In any case, reduction in emissions from fossil fuels involves major restructuring of the economy and will take a considerable time to achieve. Whilst agriculture is a significant source of GHG emissions, part of which derives from landuse change and land management practices, there has also been considerable discussion of the potential of soil as a carbon sink (Sanderman et al., 2010) which might mitigate carbon emissions from agriculture and other sectors of the economy. With appropriate management practices, $\mathrm{C}$ sequestration in soil has the potential to proceed quickly and thus play a bridging role as the restructuring of the economy required to reduce emissions from fossil fuel takes place (Bangsund \& Leistritz, 2007; Chan et al., 2012; Lal, 2000).

In 2011 the Australian Government introduced the Carbon Farming Initiative (CFI) which includes a carbon offsets scheme to promote sequestration of carbon in soil and trees (DCCEE, 2011). While the CFI provides a framework within which farmers could potentially be rewarded for additional $\mathrm{C}$ sequestered in soil, there is currently no approved methodology and the most effective land management responses have yet to be identified. At any particular location, an increase in soil carbon requires increased carbon input, usually from plant growth, as well as minimizing losses due to OM decomposition and soil movement. As the factors affecting carbon inputs and losses show considerable variation by region (e.g. soil type, land use patterns and history, land management practices and climate) (Sanderman et al., 2010), recommendations for farmers who want to participate in $\mathrm{C}$ sequestration programs will need to be region-specific and based, as much as possible, on the results of local investigations. Further, there is only limited region-specific information available to farmers who wish to participate in the CFI as to which soil and land management practices are most suitable for sequestration 
of carbon (Stokes \& Howden, 2010). Because there is an upper limit to the amount of carbon that can be sequestered in a soil (Stewart et al., 2007), the current soil carbon level is a strong determinant of the amount that can be sequestered under any change in management practices, in effect setting an upper, technical limit. In addition, economic feasibility of management practices may mean that the increases actually achieved are much less than the technical upper limit (Bangsund \& Leistritz, 2007). As there are considerable regional differences in all these variables as well as in climate, the major determinant of the amount of plant residues available to incorporate in soil, information to assist primary producers in decisions related to carbon sequestration in soil will be needed on a regional basis.

In North West NSW it is clear that the change in landuse from native vegetation to cultivation is accompanied by a significant loss of soil carbon (as measured by both concentration and stock). Further, continuous cotton growing lead to declining soil fertility and cotton yields. An ongoing major research program in soils of the cotton growing areas (with emphasis on Vertosols) continues the search for crop sequences and management strategies that improve soil quality, facilitate soil organic carbon sequestration, maximize economic returns and improve water use efficiency. This considerable body of work is reviewed by Hulugalle and Scott (2012).

In contrast, there has been much less attention to the soils on which cotton is not grown. The typical landuses in these soils are uncultivated pastures of native grasses from which most trees have been cleared, improved pastures established with cultivation, and land that has been cultivated for varying periods of time, mostly for wheat and other cereals. The need now is to assess baseline soil organic carbon levels and the factors affecting them and to identify and evaluate management systems to improve production while maintaining soil fertility. Young et al. (2005) sampled soils at 7 sites under woodlands, perennial pasture with or without lucerne, and continuous cropping, to a depth of $1.00 \mathrm{~m}$. Up to $0.20 \mathrm{~m}$, organic carbon stocks and concentration were mostly similar for woodlands and pasture which were, in turn, greater than the values for soils under cropping. However, when sampled to $1.0 \mathrm{~m}$, carbon stocks under woodland were greater than those for both pasture and cropping.

In a similar observational field study, Wilson et al. (2011) sampled woodland, pasture (improved and unimproved), and cultivated soil, to $0.30 \mathrm{~m}$. Both carbon concentration and stocks under woodland were greater than under pasture or cropping. However, in contrast to the results of Young et al, there was no difference in carbon concentration or stocks between pasture and cultivation.

We report here on initial efforts in the Namoi Catchment Management Authority (CMA) in North West NSW, Australia to provide information to primary producers on the levels of soil carbon, and variation with landuse and soil texture, to assist them in making decisions related to the CFI.

The CMA considers soil health as fundamental to all activities in the catchment area - the Foreword of the Namoi Catchment Action Plan identifies the need to sequester carbon in the landscape (Namoi CMA, 2012a). "Storage of organic matter and in particular carbon" are seen as critical aspects of soil health (Namoi CMA, 2012b). Under its 2010-20 Catchment Action Plan, the Namoi CMA is investing in soil carbon improvement using a resilience framework. The work is part of the Australian Government Caring for Our Country 'Increasing Soil Carbon Sequestration through Improving Land Management Practices (Soil Carbon Program)'. As part of this Program the CMA undertook baseline soil sampling and specific laboratory determinations at 37 locations in 2010-11. Apart from providing local information on the soil carbon situation and the factors affecting it, the results are expected to serve as a baseline against which change in the ensuing 5 years can be measured and monitored.

\section{Methods}

The basic protocol used by the CMA has been adapted from the protocol used by the NSW Office of Environment and Heritage (Chapman et al., 2011).

\subsection{Study Area}

The study sites are all located in the eastern part of the Namoi Catchment Management Authority (see Figure 1), essentially the Northwest Slopes and Plains of the state of New South Wales, Australia on farms in the Boggabri, Curlewis, Gunnedah, Narrabri, Somerton and Quirindi districts. Soils were sampled between May and August 2011 during the autumn-winter season. Soils in the area are predominantly Vertosols, Kurosols, Calcarosols and Chromosols. Land degradation is an important issue within the catchment with low levels of soil carbon in many areas (Chapman et al., 2011; Namoi CMA, 2012b). 


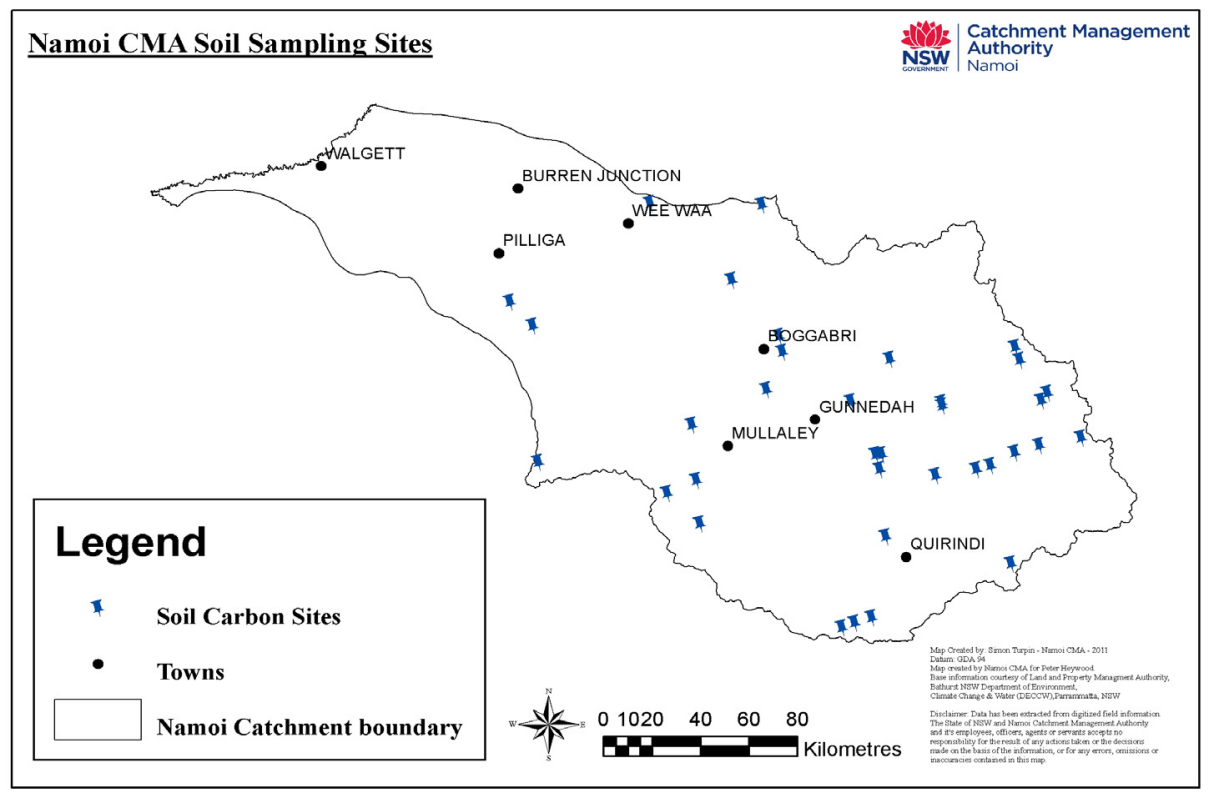

Figure 1. Soil sampling sites, Namoi Catchment Management Authority, NSW, Australia

Average annual rainfall in these locations varies between 580 and $680 \mathrm{~mm}$ with a pronounced winter trough and summer peaks. In all areas the mean maximum temperatures exceed $30^{\circ} \mathrm{C}$ in December and January; the mean minimum temperature is lowest in July but, in all areas, is greater than $0^{\circ} \mathrm{C}(\mathrm{BOM}, 2012)$.

\subsection{Design and Sampling}

In this observational field study, the results and analyses reported form the baseline measurements for assessment of carbon sequestration in the Namoi CMA under the "Increasing Soil Carbon Sequestration through Improving Land Management Practices (Soil Carbon Program)". Baseline soil sampling to $10 \mathrm{~cm}$ was undertaken on a subset of 37 of the 50 farms included in the soil carbon program. In a further subset of 12 (of the 37) farms, sampling was to a depth of $30 \mathrm{~cm}$. At each of the 37 locations, 2 sites were sampled, one within the area in which land management practices would be according to agreements with the Namoi CMA (hereafter referred to as the 'treatment' site) and the other outside the treatment area but with similar land use history and landform, but no agreement as to subsequent land use, hereafter referred to as the 'reference' site. At each site baseline photo points and groundcover assessments were made and a land use history taken. Additional sampling at both treatment and reference sites is planned for 2016 to measure and monitor eventual variation.

The treatment and reference locations were selected to ensure they were representative of treatment, land use and soil type, part of a single landform unit as defined by slope and access, not located near unusual land use features (e.g. stock watering points, stock camps, tracks and gates, headlands, sheds or yards), at least $10 \mathrm{~m}$ from a fence, and accessible by motor vehicle and soil core trailer.

Soil samples were taken and laboratory analyses completed from a total of 74 sites ( 2 sites - 1 'treatment' and 1 'reference' - for each of 37 farms).

Each site was identified by a Namoi CMA Monitoring Point and laid out as follows:

- $\quad$ Each site is a $25 \mathrm{~m} \times 25 \mathrm{~m}$ square;

- After choosing a point, for which a GPS reading was recorded, a $25 \mathrm{~m}$ x $25 \mathrm{~m}$ square was laid out using the point as the SW corner and recording its relation to the monitoring tag placed on the closest permanent landmark (e.g. fence, tree) using a compass and range finder;

- A GPS photograph was taken of the monitoring tag;

- The site was photographed from SW to NE using a GPS camera;

- Core sample locations were chosen within the $25 \mathrm{~m}$ x $25 \mathrm{~m}$ square such that no two locations were within 4 $\mathrm{m}$ of each other. 
Soil sampling was carried out as follows:

- At each sampling site, 16 (10 for soil carbon testing and 6 for bulk density testing) core samples were taken using a $26 \mathrm{~mm}$ inside diameter coring tube from sites within the boundaries of the $25 \mathrm{~m} \mathrm{x} 25 \mathrm{~m}$ square (see above) ensuring that no two sites were within $4 \mathrm{~m}$ of each other and that the site was free of rocks and vegetation. 10 soil cores were taken to a depth of $20 \mathrm{~cm}$ (for $10 \mathrm{~cm}$ sampling) or to a depth of $50 \mathrm{~cm}$ (for 30 $\mathrm{cm}$ sampling) to ensure a good quality core;

- Depending on the depth, each core was divided into 0-5 cm, 5-10 cm, 10-20 cm and 20-30 cm;

- The 10 soil carbon samples were bulked by depth, placed in plastic bags and refrigerated for sending to the laboratory;

- $\quad$ Similarly, the 6 samples taken for bulk density were bulked by depth, placed in a plastic bag, refrigerated and labelled for sending to the laboratory. The depth of the hole and the length of the cores were measured separately;

- Location and land use history were recorded based on information supplied by the farmer;

- $\quad$ All information was recorded on a standard Field Data Form.

\subsection{Laboratory Analyses}

Analyses were made by East West Enviroag Pty Ltd, Tamworth, NSW, Australia using standard laboratory methods as follows:

- $\quad$ Phosphorus - method 9B1 (Rayment \& Lyons, 2011);

- $\quad$ Moisture - method 2B1 (Rayment \& Lyons, 2011);

- $\quad$ Total and organic carbon LECO analyser - method 6B2 (Raymond \& Lyons, 2011)

- Bulk density - intact core method 503.01 (Cresswell \& Hamilton, 2002);

- $\quad$ Texture - methods as described in (Fitzpatrick et al., 2001).

- $\quad$ Fixed depth carbon density ( $\mathrm{t} / \mathrm{ha}$ ) for each depth interval was calculated as the product of soil volume, bulk density and soil organic carbon (\%).

- $\quad$ Statistical analysis was carried out using Stata Version 9 (StataCorp, Texas, USA).

\section{Results}

\subsection{Land Use in Last 10 Years (Figure 2)}

Virgin native pasture ( $\mathrm{n}=20)$ and cropping (19) accounted for more than half of the land use in the past 10 years. The remainder included regenerated native pasture, other pasture, and pasture+cropping.

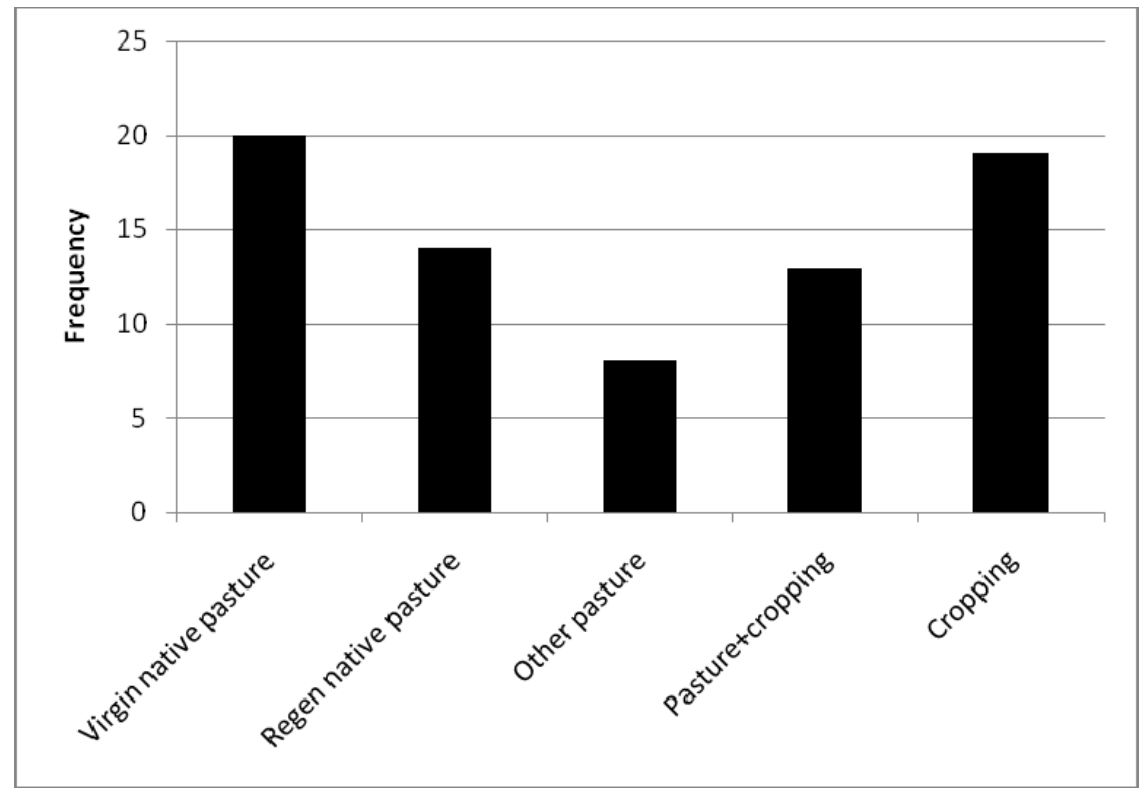

Figure 2. Frequency distribution of landuse (last 10 years) categories 


\subsection{Soil Texture (Figure 3)}

The texture classes ranged from loamy sand to medium clay. The modal class was clay loam $(n=19)$ followed by sandy clay (14), medium clay (13), and fine sandy clay loam (10). All other texture classes had frequencies less than 10 .

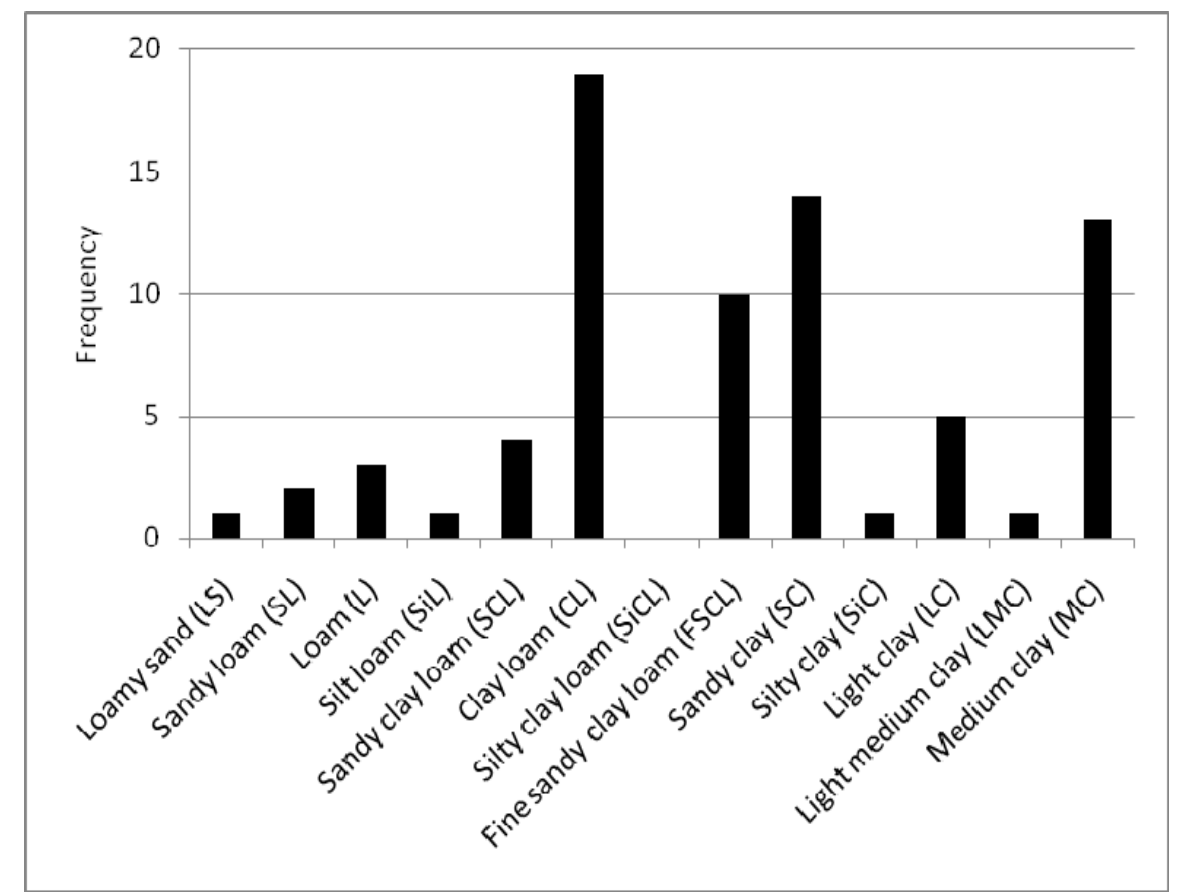

Figure 3. Frequency distribution of soil texture classes $(0-5 \mathrm{~cm})$

\subsection{Land Use $x$ Soil Texture}

To allow investigation of the joint effects of land use in the last 10 years and soil texture the sites were classified by both variables - For land use the categories were 'virgin native pasture' and 'other'; while soil texture was divided in samples above and below $30 \%$ clay. The joint $2 \times 2$ distribution is shown in Table 1 .

Table 1. Joint frequency distribution of land use in the last 10 years and soil texture $(0-5 \mathrm{~cm})$

\begin{tabular}{llll}
\hline Texture & Land use last 10 years & \\
\hline & Virgin native pasture & Other & Total \\
$<30 \%$ clay & 4 & 7 & 11 \\
$>30 \%$ clay & 16 & 47 & 63 \\
Total & 20 & 54 & 74 \\
\hline
\end{tabular}

This classification was then used to test for the main effects and interaction of land use and soil texture on bulk density and carbon density using ANOVA unbalanced design.

\subsection{Laboratory Analyses}

The results of laboratory analyses by depth of sample are shown in Table 2. Overall, there was a decrease in phosphorus, soil organic carbon and total carbon, and an increase in soil bulk density, with depth up to $10 \mathrm{~cm}$ but not below. 
Table 2. Summary of laboratory results by depth of sample

\begin{tabular}{llllllll}
\hline Variable & Depth $(\mathrm{cm})$ & $\mathrm{N}$ & Mean & SD & Min & Max & P value \\
\hline Phosphorus & $0-5$ & 74 & 52.8 & 50.9 & 13.4 & 290.0 & \multirow{2}{*}{0.03} \\
(Colwell) & $5-10$ & 74 & 38.3 & 42.8 & 7.2 & 226.8 & \\
$\mathrm{mg} / \mathrm{kg}$ & $10-20$ & 12 & 36.0 & 30.7 & 14.6 & 122.0 & 0.54 \\
& $20-30$ & 12 & 37.6 & 38.7 & 7.0 & 121.0 & \\
Soil organic carbon & $0-5$ & 74 & 2.4 & 1.2 & 0.6 & 6.4 & \\
$(\%)$ & $5-10$ & 74 & 1.4 & 0.6 & 0.6 & 3.9 & $<.001$ \\
& $10-20$ & 12 & 0.9 & 0.6 & 0.4 & 2.6 & \\
& $20-30$ & 12 & 0.8 & 0.6 & 0.2 & 2.2 & 0.34 \\
Total carbon & $0-5$ & 74 & 2.6 & 1.2 & 0.7 & 6.5 & \\
$(\%)$ & $5-10$ & 74 & 1.6 & 0.7 & 0.6 & 3.9 & $<.001$ \\
& $10-20$ & 12 & 1.1 & 0.7 & 0.5 & 2.9 & \\
& $20-30$ & 12 & 0.9 & 0.7 & 0.3 & 2.4 & 0.25 \\
Carbon density & $0-5$ & 72 & 15.2 & 6.3 & 4.3 & 34.3 & \\
(t/ha) & $5-10$ & 72 & 9.9 & 3.7 & 4.3 & 22.4 & $<.001$ \\
& $10-20$ & 12 & 6.6 & 3.4 & 2.8 & 15.2 & \\
& $20-30$ & 12 & 5.4 & 3.3 & 1.6 & 12.5 & 0.19 \\
Bulk density & $0-5$ & 72 & 1.3 & 0.2 & 0.9 & 1.7 & \\
g/cm ${ }^{3}$ & $5-10$ & 72 & 1.4 & 0.1 & 1.2 & 1.8 & $<.001$ \\
& $10-20$ & 12 & 1.5 & 0.2 & 1.2 & 1.8 & \multirow{2}{*}{0.50} \\
& $20-30$ & 12 & 1.5 & 0.2 & 1.2 & 1.7 & \\
\hline
\end{tabular}

Note: at 10-20 cm and 20-30 cm sampling was made on a sub-sample of 12 sites.

\subsection{Effect of Land Use and Soil Texture on Bulk Density (Table 2 and Table 3)}

Bulk density increased with depth up to $10 \mathrm{~cm}$ (Table 2). There was a significant effect of land use on bulk density at $0-5 \mathrm{~cm}$ (Table 3), virgin native pasture having a significantly lower bulk density than soils in which land use was 'other'. There was no effect of soil texture on bulk density at 0-5 $\mathrm{cm}$. Neither land use nor soil texture had a significant effect on bulk density at $5-10 \mathrm{~cm}$ (not shown).

Table 3. Bulk density $\left(\mathrm{g} / \mathrm{cm}^{3}\right), 0-5 \mathrm{~cm}$, by land use in last 10 years and soil texture

\begin{tabular}{llll}
\hline Land use last 10 years & \multicolumn{2}{l}{ Soil texture (\%clay) } & All texture \\
\hline & $<30 \%$ & $>30 \%$ & \\
Virgin native pasture & 1.28 & 1.21 & 1.22 \\
Other & 1.40 & 1.33 & 1.34 \\
All land use & 1.36 & 1.30 & 1.31 \\
& & & \\
Analysis of variance & & & \\
Variable & $\mathrm{F}$ & $\mathrm{p}$ & \\
Model & 3.32 & 0.0248 & \\
Soil texture & 1.83 & 0.1808 & \\
Land use & 5.41 & 0.0231 & \\
Interaction & 0.01 & 0.9257 & \\
\hline
\end{tabular}

\subsection{Effect of Land Use and Soil Texture on Soil Carbon}

There was a strong land use effect on soil organic carbon (\%) and a significant effect of texture at both $0-5 \mathrm{~cm}$ and $5-10 \mathrm{~cm}$, with no interaction. The most disturbed soils with the lowest clay content had the lowest soil 
organic carbon (\%); the highest soil organic carbon was found in soils with the most clay and the least disturbance. The results for $0-5 \mathrm{~cm}$ are shown in Table 4.

Table 4. Mean soil organic carbon (\%) $0-5 \mathrm{~cm}$ by land use in last 10 years and soil texture

\begin{tabular}{llll}
\hline Land use last 10 years & \multicolumn{2}{l}{ Soil texture (\%clay) } & All texture \\
& $<30 \%$ & $>30 \%$ & \\
\hline Virgin native pasture & 2.72 & 3.22 & 3.12 \\
Other & 1.10 & 2.36 & 2.20 \\
All land use & 1.69 & 2.58 & 2.44 \\
& & & \\
Analysis of variance & & & \\
Variable & $\mathrm{F}$ & $\mathrm{p}$ & \\
Model & 6.35 & 0.0007 & \\
Soil texture & 5.40 & 0.0230 & \\
Land use & 10.72 & 0.0016 & \\
Interaction & 1.01 & 0.3188 & \\
\hline
\end{tabular}

The effects of land use and soil texture on carbon density were similar to those for soil carbon (\%) - both factors had a significant effect at both 0-5 cm (Table 5) and 5-10 cm (Table 6), with no interaction. The highest carbon density was for soils with the most clay and the least disturbance.

Table 5. Mean Carbon density $0-5 \mathrm{~cm}(\mathrm{t} / \mathrm{ha})$ by land use in last 10 years and soil texture

\begin{tabular}{|c|c|c|c|}
\hline \multirow[t]{2}{*}{ Land use last 10 years } & \multicolumn{2}{|c|}{ Soil texture (\%clay) } & \multirow[t]{2}{*}{ All texture } \\
\hline & $<30 \%$ & $>30 \%$ & \\
\hline Virgin native pasture & 17.7 & 19.1 & 18.8 \\
\hline Other & 7.7 & 14.8 & 13.9 \\
\hline All land use & 11.3 & 15.9 & 15.2 \\
\hline \multicolumn{4}{|l|}{ Analysis of variance } \\
\hline Variable & $\mathrm{F}$ & $\mathrm{p}$ & \\
\hline Model & 6.97 & 0.0004 & \\
\hline Land use & 13.58 & 0.0005 & \\
\hline Soil texture & 4.82 & 0.0316 & \\
\hline Interaction & 2.19 & 0.1437 & \\
\hline
\end{tabular}

Table 6. Mean Carbon density $5-10 \mathrm{~cm}(\mathrm{t} / \mathrm{ha})$ by land use in last 10 years and soil texture

\begin{tabular}{llll}
\hline Land use last 10 years & \multicolumn{2}{l}{ Soil texture (\%clay) } & All texture \\
\hline & $<30 \%$ & $>30 \%$ & \\
Virgin native pasture & 8.9 & 12.3 & 11.6 \\
Other & 6.8 & 9.9 & 9.3 \\
All land use & 7.4 & 10.5 & 9.9 \\
& & & \\
Analysis of variance & & & \\
Variable & $\mathrm{F}$ & $\mathrm{P}$ & \\
Model & 5.3 & 0.0024 & \\
Land use & 8.08 & 0.0496 & \\
Soil texture & 8.08 & 0.0059 & \\
Interaction & 0.02 & 0.8832 & \\
\hline
\end{tabular}


The levels for both carbon $\%$ and carbon density at $5-10 \mathrm{~cm}$ were significantly lower than the levels at $0-5 \mathrm{~cm}$ $(\mathrm{p}<0.0001)$ (not shown).

\section{Discussion}

\subsection{Level of Carbon}

There is a wide (10-fold) range of carbon content in these soils for $0-5 \mathrm{~cm}$ - from $0.63 \%$ to $6.35 \%$, and a quarter of the samples contained less than $1.5 \%$; and carbon densities for $0-10 \mathrm{~cm}$ depth range from 8.6 to $56.7 \mathrm{t} \mathrm{C} / \mathrm{ha} / 10$ $\mathrm{cm}$.

The results most directly comparable with ours are those for Wilson et al. (2011) who assessed the effect of land use on carbon levels of soils in the Northern Tablelands and Northwest Slopes of NSW. They present their results by $5 \mathrm{~cm}$ depth intervals allowing calculation of carbon density for $0-10 \mathrm{~cm}$ for comparison with our results. The mean carbon density $0-10 \mathrm{~cm}$ in their study is $31.1 \mathrm{t} \mathrm{C} / \mathrm{ha} / 10 \mathrm{~cm}$ compared with our overall mean of $25.1 \mathrm{t}$ $\mathrm{C} / \mathrm{ha} / 10 \mathrm{~cm}$. As their study included woodlands as well as land under pasture and cultivation it is not surprising that they have a slightly higher mean.

\subsection{Effect of Landuse}

Wilson et al. (2011) also estimated the effect of land use on carbon \%. Land under pasture had a significantly higher carbon content than that under cultivation. Again, this is very similar to our results in which there was a strong effect of land use (soils used for pasture had higher carbon \% and carbon density than cultivated soils). Young et al. (2005), also in northern NSW, showed comparable values and that cultivated soils have significantly less carbon than those under pasture or woodlands.

The effect of land use, which basically shows that disturbance consequent on cultivation leads to lower soil carbon levels, is consistent with those of CSIRO (2009) and Stokes and Howden (2010) who conclude that the conversion of temperate ecosystems to agriculture leads to depletion of soil organic carbon by up to $70 \%$ (Young et al., 2005).

\subsection{Effect of Soil Texture}

Our results showing that soils with higher clay content have a higher carbon content are also consistent with those in the literature (Baldock \& Skjemstad, 2000; CSIRO, 2009). Similar to the findings of Young et al. (2005) and Wilson et al. (2011), there was no interaction between soil texture and land use history, that is, the effects of land use were similar on soils of varying clay content.

\section{4 Implications}

As in other countries, the introduction of settled agriculture into the Australian landscape resulted in the depletion of soil carbon stocks. This depletion now represents an opportunity for soil sequestration of carbon, an important environmental service. Thus, even taking into account that it is not possible to return to the pre-disturbance levels (Lal, 2000) and that there is an upper limit to the amount of carbon it is possible to sequester (Stewart et al., 2007), there is considerable potential for some of these sites to act as carbon sinks (Chan et al., 2012; CSIRO, 2009; Parliament of Victoria, 2010; Sanderman et al., 2010; Stokes \& Howden, 2010). Consequently, soils are now seen by some as a potentially low cost sink which, under the right circumstances, could sequester significant amounts of carbon in the short term and act as a stop gap measure while other economic and social changes in favour of reducing $\mathrm{C}$ emissions are implemented (Bangsund \& Leistritz, 2007; Stokes \& Howden, 2010).

Taking advantage of this potential for carbon sequestration requires deliberate planning and management at the farm and landscape levels using the best current practices (Chan et al., 2012; Sanderman et al., 2010) to:

- $\quad$ preserve the carbon that is already there;

- $\quad$ increase input of carbon to the soil;

- $\quad$ minimize mineralization; and

- minimize movement of soil from erosion.

Soil erosion, long an important issue in this region of NSW (Chapman et al., 2011), will be a critical factor in the success of attempts to sequester carbon at a given location (Gregorich et al., 1998; McCarty \& Ritchie, 2002; Powlson et al., 2011). Climate change projections indicate increased variability of rainfall with increased frequency of both droughts and high intensity rainfall. Maintaining ground cover to minimize erosion and the 
resulting carbon movement will be a major management issue under these circumstances and is a priority in the Namoi CMA work program (Namoi CMA, 2012a).

To achieve this carbon sequestration potential, land managers in Australia and around the world will require detailed and organised knowledge of the local spatial distribution of soil types and textures, estimates of their carbon content and good evaluations of the various land management practices they might use to increase carbon input without increasing emissions from other related activities.

Further, land managers will have to make trade-offs between current profitable activities and those likely to increase sequestration of carbon but, often, with lower financial returns. To put it another way, the trade-off is between appropriation of ecosystem services for human use and unintended negative effects on the ecosystem itself (DeFries et al., 2004). The extent to which the wider society is willing to compensate the land managers for these lower returns even as they deliver the environmental services valued by the broader society will ultimately depend on social values and on quantitative analyses of the consequences at a range of temporal and spatial scales (Bangsund \& Leistritz, 2007; DeFries et al., 2004). The work reported here represents a start to those region-specific analyses in the Namoi Catchment.

\section{References}

Baldock, J., \& Skjemstad, J. O. (2000). Role of the soil matrix and minerals in protecting natural organic materials against biologic attack. Organic Geochemistry, 31, 697-710. http://dx.doi.org/10.1016/S0146-6380(00)00049-8

Bangsund, D. A., \& Leistritz, F. L. (2007). Review of literature on economics and policy of carbon sequestration in agricultural soils. Management of Environmental Quality, 19, 85-99. http://dx.doi.org/10.1108/14777830810840381

BOM. (2012). Bureau of Meteorology. Climate statistics for Australian sites. Retrieved May 20, 2012, from http://www.bom.gov.au/climate/averages/tables/ca_nsw_names.shtml

Chan, K. Y., Oates, A., Liu, D. L., Li, G. D., Prangnell, R., Poile, G., \& Conyers, M. K. (2012). A farmer's guide to increasing soil organic carbon under pastures. Industry and Investment NSW, Wagga Wagga, NSW, Australia.

Chapman, G., Gray J, Murphy, B., Atkinson, G., Leys, J., Muller, R., ... Yang, X. (2011). Assessing the condition of soils in NSW, Monitoring, evaluation and reporting program, Technical report series. Office of Environment and Heritage, Sydney, Australia.

Cresswell, H. P., \& Hamilton, G. J. (2002). Bulk density and pore space relations. In N. McKenzie, K. Coughlan \& H. Cresswell (Eds.). Soil physical measurement and interpretation for land evaluation. Collingwood, Victoria: CSIRO Publishing.

CSIRO. (2009). An analysis of greenhouse gas mitigation and carbon biosequestration opportunities from rural land use. National Research Flagships. Sustainable Agriculture. CSIRO.

DCCEE. (2011). Carbon Farming Initiative. Department of Climate Change and Energy Efficiency, Australian Government. Retrieved March 30, 2012, from http://www.climatechange.gov.au/landsectormeasures

DCCEE. (2012). Australian National Greenhouse Accounts. Quarterly Update of Australia's National Greenouse Gas Inventory. December Quarter 2011. Deparrtment of Climate Change and Energy Efficiency.

DeFries, R. S., Foley, J. A., \& Asner, G. P. (2004). Land-use choices: balancing human needs and ecosystem $\begin{array}{lllll}\text { function. } & \text { Fron } & \text { Ecol } & \text { Environ, } & 249-257 .\end{array}$ http://dx.doi.org/10.1890/1540-9295(2004)002[0249:LCBHNA]2.0.CO;2

Fitzpatrick, R. W., McKenzie, N., \& Maschmedt, D. J. (2001). Soil morphological indicators and their importance to soil fertility. In K. I. Peverill, L. A. Sparrow, \& D. J. Reuter (Eds.). Soil analysis: an interpretation manual. Collingwood, Victoria: CSIRO Publishing.

Gregorich, E. G., Greer, K. J., Anderson, D. W., \& Liang, B. C. (1998). Carbon distribution and losses: erosion and deposition effects. Soil \& Tillage Research, 47, 291-302. http://dx.doi.org/10.1016/S0167-1987(98)00117-2

Hulugalle, N. R., \& Scott, F. (2012). A review of the changes in soil quality and profitability accomplished by sowing rotation crops after cotton in Australian Vertosols from 1970 to 2006. Australian Journal of Soil Research, 46, 173-190. http://dx.doi.org/10.1071/SR07077

Lal, R. (2000). World cropland soils as a source or sink for atmospheric carbon. Advances in Agronomy, 71, 
145-191. http://dx.doi.org/10.1016/S0065-2113(01)71014-0

McCarty, G. W., \& Ritchie, J. C. (2002). Impact of soil movement on carbon sequestration in agricultural ecosystems. Environmental Pollution, 116, 423-430. http://dx.doi.org/10.1016/S0269-7491(01)00219-6

Namoi CMA. (2012a). Namoi Catchment Action Plan 2010-2020. http://www.namoi.cma.nsw.gov.au/draft_cap_september_2011_for_website_1.pdf. Accessed 30-3-2012

Namoi CMA. (2012b). Soil health. Retrieved from http://www.namoi.cma.nsw.gov.au/73.html? Accessed $11 / 05 / 12$.

Parliament of Victoria. (2010). Inquiry into soil carbon sequestration in Victoria. Environment and Natural Resources Committee of the Parliament of Victoria.

Powlson, D. S., Gregory, P. J., Whalley, W. R., Quinton, J. N., Hopkins, D. W., Whitmore, A. P., ... Goulding, K. W. T. (2011). Soil management in relation to sustainable agriculture and ecosystem services. Food Policy, 36, 572-587. http://dx.doi.org/10.1016/j.foodpol.2010.11.025

Rayment, G. E., \& Lyons, D. J. (2011). Soil chemical methods-Australasia. Collingwood, Victoria: CSIRO Publishing.

Sanderman, J., Farquharson, R., \& Baldock, J. (2010). Soil carbon sequestration potential: a review for Australian agriculture. CSIRO. A report prepared for the Department of Climate Change and Energy Efficiency, Commonwealth of Australia.

Stewart, C. E., Paustian, K., Conant, R. T., Plante, A. F., \& Six, J. (2007). Soil carbon saturation: concept, evidence and evaluation. Biogeochemistry, 86, 19-31. http://dx.doi.org/10.1007/s10533-007-9140-0

Stokes, S., \& Howden, M. (2010). Adapting agriculture to climate change. Collingwood, Victoria: CSIRO Publishing.

Wilson, B. R., Koen, T. B., Barnes, P., Ghosh, S., \& King, D. (2011). Soil carbon and related soil properties along a soil type and land-use intensity gradient, New South Wales, Australia. Soil Use and Management, 27, 437-447. http://dx.doi.org/10.1111/j.1475-2743.2011.00357.x

Young, R., Wilson, B. R., McLeod, M., \& Alston, C. (2005). Carbon storage in the soils and vegetation of contrasting landuses in northern New South Wales, Australia. Australian Journal of Soil Research, 43, 21-31. http://dx.doi.org/10.1071/SR04032 